\title{
Effect of Photodynamic Antimicrobial Chemotherapy on in vitro and in situ Biofilms
}

\author{
A.H. Teixeira ${ }^{\text {a }}$ E.S. Pereira ${ }^{\text {b }} \quad$ L.K.A. Rodrigues ${ }^{a} \quad$ D. Saxena ${ }^{d} \quad$ S. Duarte ${ }^{d}$ \\ I.C.J. Zanin ${ }^{\mathrm{C}}$ \\ ${ }^{a}$ Faculty of Pharmacy, Dentistry and Nursing, Federal University of Ceara, Fortaleza, ${ }^{\mathrm{b}}$ Medical School, and ${ }^{\mathrm{C}}$ Faculty \\ of Dentistry, Federal University of Ceara, Sobral, Brazil; ${ }^{d}$ Department of Basic Sciences, New York University College \\ of Dentistry, New York, N.Y., USA
}

\section{Key Words}

Biofilms · In situ study $\cdot$ Photodynamic antimicrobial chemotherapy $\cdot$ Streptococcus mutans

\begin{abstract}
Aim: The effect of photodynamic antimicrobial chemotherapy (PACT) on oral biofilms was evaluated. Methods: Biofilms formed in vitro were treated with sensitizer (S) and/or light $(\mathrm{L})$ in the test $\left(\mathrm{S}^{+} \mathrm{L}^{+}\right)$and control $\left(\mathrm{S}^{-} \mathrm{L}^{-}, \mathrm{S}^{+} \mathrm{L}^{-}, \mathrm{S}^{-} \mathrm{L}^{+}\right)$groups. Additionally, 21 volunteers wore intraoral devices and the biofilms formed on each side of the device were referred to as $\mathrm{S}^{+} \mathrm{L}^{+}$or $\mathrm{S}^{-} \mathrm{L}^{-}$groups. Results: Significant decreases in the viability of in vitro biofilms were observed after PACT. PACT was ineffective in inhibiting multi-species biofilms formed in situ. Conclusion: PACT was effective on in vitro biofilms and was ineffective on in situ biofilms.
\end{abstract}

Copyright $\odot 2012$ S. Karger AG, Basel

Decades of epidemiological, biochemical, and animal studies reported that streptococci generally comprise the majority of dental plaque microorganisms [Pratten et al., 2003] and implicated Streptococcus mutans as the princi- pal causative agent of dental caries [Lemos and Burne, 2008]. It is also known that cells growing in biofilms can alter gene expression, resulting in many organisms having a radically different phenotype following attachment to a surface [Shemesh et al., 2007]. Furthermore, an important clinical consequence of both the structural organization of biofilms and the subsequent altered pattern of gene expression is the reduced susceptibility of cells to antimicrobial agents. The age and the structure of a biofilm may also restrict the penetration of the antimicrobial agent and leave cells in the depths of the biofilm relatively unaffected [Zanin et al., 2005]. In addition, disruption of the oral microflora and the difficulty of maintaining therapeutic concentrations of antimicrobials in the oral cavity are also problems associated with the use of these agents [Zaura-Arite et al., 2001].

Alternative tools such as photodynamic antimicrobial chemotherapy (PACT) entered the dentistry field as a therapeutic option to kill bacteria in oral biofilms [Zanin et al., 2005] or dental caries [Lima et al., 2009]. PACT is a process in which microorganisms are treated with a photosensitizing drug and then irradiated with low-intensity visible light of the appropriate wavelength. The resulting photochemical reactions generate cytotoxic reactive oxy-

\section{KARGER}

Fax +4161306 1234

E-Mail karger@karger.ch

www.karger.com (c) 2012 S. Karger AG, Basel

$0008-6568 / 12 / 0466-0549 \$ 38.00 / 0$

Accessible online at:

www.karger.com/cre
Iriana Carla Junqueira Zanin

Faculty of Pharmacy, Dentistry and Nursing, Federal University of Ceara

Cap. Francisco Pedro S/N - Rodolfo Teófilo

60430-170 Fortaleza, CE (Brazil)

Tel. +55 853366 8410, E-Mail irianaz@yahoo.com.br 
gen species, such as singlet oxygen and free radicals, which are able to exert a bactericidal effect [Wilson and Patterson, 2008].

Several studies reported the photodynamic inactivation of gram-positive and gram-negative bacteria and oral fungi using the association of different photosensitizers and light sources in planktonic cultures [Paulino et al., 2005; Rolim et al., 2012], in oral biofilms [Wood et al., 1999; O'Neill et al., 2002; Zanin et al., 2005, 2006] as well as using dental caries models [Lima et al., 2009; Melo et al., 2010]. However, other authors found that PACT failed to demonstrate significant reduction of oral pathogens, especially when multispecies biofilms were tested [Müller et al., 2007; Qin et al., 2008; Fontana et al., 2009]. In addition, there is no conclusive data about the effect of PACT on complex biofilms grown under naturally varying intraoral conditions that cannot be replicated using even the most sophisticated in vitro approaches. Therefore, the aim of this study was to evaluate the susceptibility of $S$. mutans biofilms grown in vitro and in situ to the action of PACT.

\section{Materials and Methods}

\section{Photosensitizer and Light Sources}

The photosensitizer was toluidine blue ortho (TBO, Sigma Chemicals, Poole, UK), dissolved in deionized water $(100 \mu \mathrm{g}$ $\mathrm{ml}^{-1}$ ) and stored at room temperature in the dark. A red lightemitting diode (LED; Laserbeam, Rio de Janeiro, RJ, Brazil) with a spectrum of emission ranging from 620 to $660 \mathrm{~nm}$ and predominant wavelength of $638.8 \mathrm{~nm}$ was used as a light source. A fiberoptic spot with a $9.5-\mathrm{mm}$ cylindrical diffusing tip distributed the light. Irradiation was performed in a noncontact mode with a focused beam at $2.0 \mathrm{~mm}$ of working distance. A power meter Lasermate (Coherent Inc., Santa Clara, Calif., USA) was used to measure the peak power, and a maximum output power of $40 \mathrm{~mW}$ was determined. Since noncollimated light may spread as it propagates, the area considered in the present calculation of power density of light was related to the hemisphere area [Rolim et al., 2012] and was $31.8 \mathrm{~mW} / \mathrm{cm}^{2}$. Consequently, biofilms were exposed to a $55 \mathrm{~J} \mathrm{~cm}^{-2}$ energy density after $15 \mathrm{~min}$ of irradiation.

\section{Experimental Design}

For the in vitro experiment, 36 hydroxyapatite (HA) sterile discs $\left(0.74 \mathrm{~cm}^{2}\right)$ were randomly allocated to four groups, with 12 experimental units per set of group. Biofilms of S. mutans UA159 were grown on $\mathrm{HA}$ discs immersed in bath culture and the mature biofilm was submitted to PACT after 5 days. To minimize the inherent bias related to microbiological procedures, three independent experiments were performed at different time points. The treatment conditions in which biofilms were exposed are as follows: biofilms were exposed to both $\mathrm{TBO}$ and light $\left(\mathrm{S}^{+} \mathrm{L}^{+}\right)$, biofilms were not exposed to sensitizer or light $\left(\mathrm{S}^{-} \mathrm{L}^{-}\right)$, biofilms were exposed only to sensitizer $\left(\mathrm{S}^{+} \mathrm{L}^{-}\right)$or biofilms were exposed only to light $\left(\mathrm{S}^{-} \mathrm{L}^{+}\right)$.
For the in situ experiment, a single-blind split-mouth design was used in one phase of 7 days, in which 21 volunteers wore palatal devices containing 8 human enamel slabs. At the end of the clinical phase, the device was randomly split and each half was allocated to one of the following treatments: biofilms exposed to TBO followed by irradiation with $55 \mathrm{~J} \mathrm{~cm}^{-2}$ using an LED $\left(\mathrm{S}^{+} \mathrm{L}^{+}\right)$, and biofilms not exposed to sensitizer or light $\left(\mathrm{S}^{-} \mathrm{L}^{-}\right)$. The other control conditions $\left(\mathrm{S}^{+} \mathrm{L}^{-}\right.$and $\left.\mathrm{S}^{-} \mathrm{L}^{+}\right)$were not used since they $\mathrm{did}$ not show antimicrobial action in the in vitro study.

\section{Ethical Aspects}

This study was approved by the Research and Ethics Committee of Vale do Acaraú State University (protocol number 669). All donors of saliva, donors of teeth and volunteers gave informed consent according to Resolution No. 196 of the National Health Council, Health Ministry, Brasília, DF, from 10/03/1996.

\section{In vitro Biofilm Formation}

Saliva-coated HA discs incubated with tryptic soy broth and yeast extract media with $1 \%$ of sucrose inoculated with $S$. mutans in 24-well polystyrene plates. The biofilms were then formed in the HA discs for $120 \mathrm{~h}$ with the culture medium being replaced every $24 \mathrm{~h}$ [Duarte et al., 2008]. At the end of the experimental period, the mature biofilms were washed in $\mathrm{NaCl} 0.89 \%$ solution, then submitted to treatments.

\section{PACT of in vitro Biofilms}

After 5 days of biofilm formation, HA discs containing the biofilms were transferred to other 24-well polystyrene plates containing TBO (groups $\mathrm{S}^{+} \mathrm{L}^{+}$and $\mathrm{S}^{+} \mathrm{L}^{-}$) or sterile Milli-Q water (groups $\mathrm{S}^{-} \mathrm{L}^{-}$and $\mathrm{S}^{-} \mathrm{L}^{+}$) during the preirradiation time of $5 \mathrm{~min}$ in the dark. Following this time, the biofilms were exposed for 15 min to LED irradiation (groups $\mathrm{S}^{+} \mathrm{L}^{+}$and $\mathrm{S}^{-} \mathrm{L}^{+}$) or maintained at room temperature during the same period (groups $\mathrm{S}^{+} \mathrm{L}^{-}$and $\mathrm{S}^{-} \mathrm{L}^{-}$). The biofilms were then scraped with a sterile spatula and transferred to a preweighed microtube containing $1 \mathrm{ml}$ of $\mathrm{NaCl}$ $0.89 \%$ solution. To disperse the biofilm, 2 pulses of $10 \mathrm{~s}$ with a 1-min interval at an output of $7 \mathrm{~W}$ were performed (Branson Sonifier 150; Branson Ultrasonics, Danbury, Conn., USA). Ten-fold serial dilutions were carried out and aliquots of pure and diluted samples were plated onto blood agar and were then incubated at $37^{\circ} \mathrm{C}, 5 \% \mathrm{CO}_{2}$ for $48 \mathrm{~h}$ before enumerating the viable microorganisms. The results were expressed as colony-forming units (CFU) per milligram of biofilm.

\section{In situ Study Population}

Twenty-one healthy volunteers (11 females and 10 males), aged 19-38 years, able to comply with the experimental protocol, were selected to participate in this study. All participants received oral and written instructions about the experimental design. The inclusion criteria were normal salivary flow rate, normal buffering capacity of saliva, and $S$. mutans colony-forming units $\left(\mathrm{CFU} \mathrm{mg} \mathrm{m}^{-1}\right.$ ) in biofilms of at least $10^{5}$ after $36 \mathrm{~h}$ of oral hygiene suspension. Exclusion criteria included active caries lesions, use of antibiotics within the past 3 months prior to the study, use of fixed or removable orthodontic devices. The use of dentifrice containing any antibiotics was suspended during the experimental period. 


\section{In situ Specimen Preparation}

Ninety sound third molars, extracted for other reasons not related to this research, previously stored in $0.01 \%(\mathrm{v} / \mathrm{v})$ thymol solution at $4{ }^{\circ} \mathrm{C}$ for 30 days, were used to manufacture 168 enamel slabs $(4 \times 4 \times 2 \mathrm{~mm})$ [Zanin et al., 2006]. The slabs were autoclaved at $121^{\circ} \mathrm{C}$ for $15 \mathrm{~min}$ and stored in $100 \%$ humidity until being inserted into the palatal appliances. An acrylic palatal device was constructed for each volunteer, in which two cavities $\left(18 \times 5 \times 3 \mathrm{~mm}^{3}\right)$ were prepared on the left and right sides; four slabs were attached with wax in each cavity. In order to allow biofilm accumulation, a plastic mesh was positioned on the acrylic resin, leaving $1 \mathrm{~mm}$ space from the slab surface [Cury et al., 2000].

\section{In situ Biofilm Formation}

Biofilms were formed under a cariogenic challenge determined by dropping a $10 \%$ sucrose solution [Aires et al., 2008] onto each enamel slab 8 times per day, according to a predetermined schedule. The volunteers were instructed to place the appliance back into the mouth 5 min after sucrose exposition [Aires et al., 2008]. No restriction was made with regard to volunteer's diet, but they were instructed to remove the appliances during meals, when consuming acid drinks or performing oral hygiene. When removed, the devices were kept moist in plastic boxes to keep the bacterial biofilm viable [Cury et al., 2000]. Throughout the entire experiment, volunteers used a dentifrice containing 1,450 $\mu \mathrm{g}$ fluoride (F) $\mathrm{g}^{-1}$, as monofluorophosphate (Colgate-Palmolive, São Paulo, SP, Brazil) and consumed optimally fluoridated water $\left(0.7 \mathrm{mg} \mathrm{F} \mathrm{l}^{-1}\right)$. At the end of the clinical phase, the two cavities of each device were randomly allocated to the treatment group $\left(\mathrm{S}^{+} \mathrm{L}^{+}\right)$ and the control group $\left(\mathrm{S}^{-} \mathrm{L}^{-}\right)$, using a computer-generated list.

\section{PACT of in situ Biofilms}

After the clinical phase the plastic meshes of the device were removed with a scalpel blade and the biofilm formed in situ was exposed. To investigate the effect of PACT, $50 \mu \mathrm{l}$ of TBO was homogeneously distributed on the biofilm formed on one side of the palatal device in a preirradiation time of $5 \mathrm{~min}$ in the dark. The other side served as a control and received $50 \mu \mathrm{l}$ of sterile water for the same period of time. TBO-treated biofilms were irradiated for $15 \mathrm{~min}$ while the control biofilm was submitted to a 15 -min waiting period in order to simulate the irradiation conditions. Biofilms were then scraped carefully and weighed, placed in $0.89 \% \mathrm{NaCl}\left(10 \mathrm{mg} \mathrm{ml}^{-1}\right)$ and sonicated as previously described. Treated and untreated samples were serially diluted and inoculated in triplicate on Mitis Salivarius agar to determine total streptococcus viability, and Mitis Salivarius agar containing 0.2 units of bacitracin $\mathrm{ml}^{-1}$ to determine the viability of mutans streptococci. Plates were incubated for $48 \mathrm{~h}$ at $37^{\circ} \mathrm{C}, 5 \% \mathrm{CO}_{2}$ and colonies were counted. The results were expressed as colony-forming units per milligram of biofilm.

\section{Statistical Analysis}

The normality distribution of the in vitro data was checked using the Kolmogorov-Smirnov statistical test. The mean and the standard deviation (SD) of the numbers of surviving microorganisms for each treatment in the in vitro and in situ experiments were calculated. Colony-forming units were transformed into $\log _{10}$ colony-forming units in order to reduce variance heterogeneity. For the in vitro study, one-way analysis of variance followed by a Tukey-Kramer test was applied to establish the differences

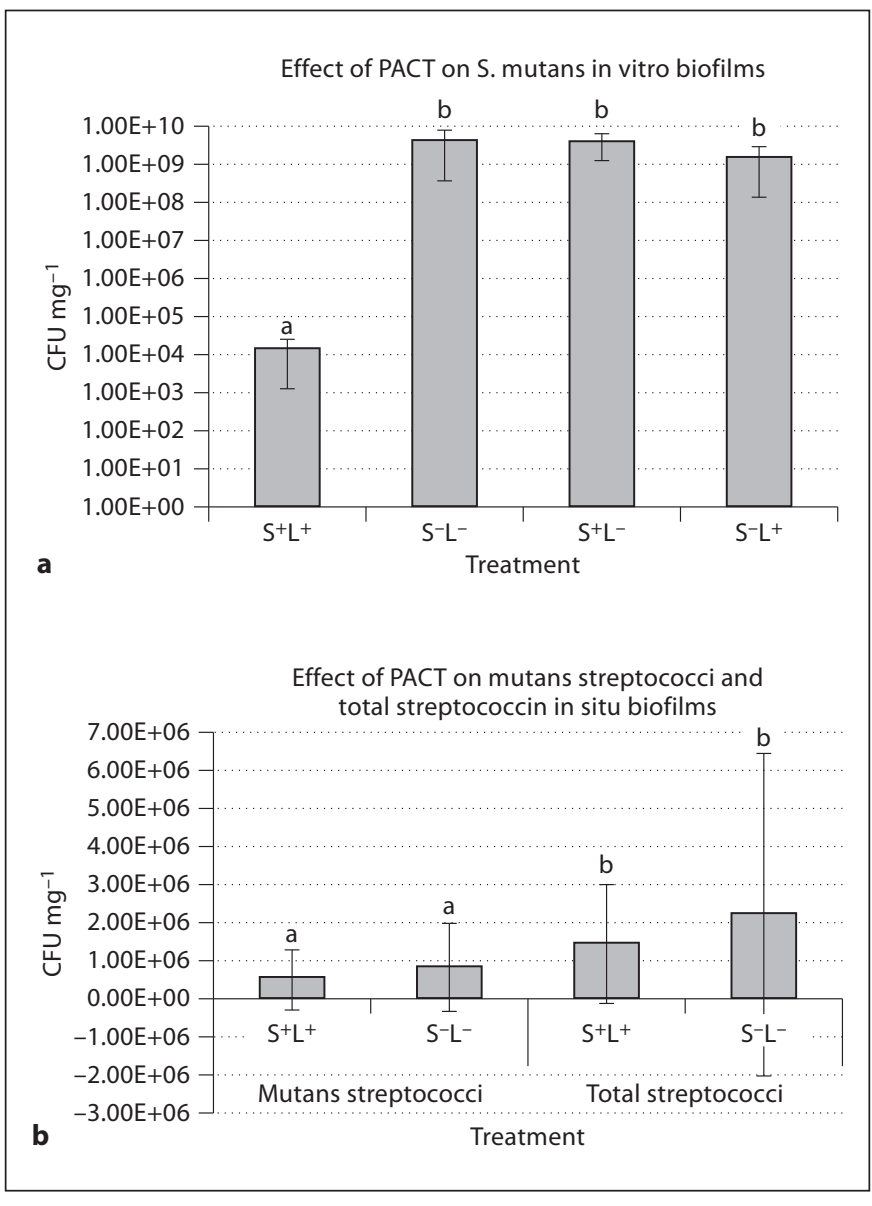

Fig. 1. a Treatment effects with sensitizer and light $\left(\mathrm{S}^{+} \mathrm{L}^{+}\right)$, without sensitizer and without light $\left(\mathrm{S}^{-} \mathrm{L}^{-}\right)$, with sensitizer and without light $\left(\mathrm{S}^{+} \mathrm{L}^{-}\right)$, and without sensitizer and with light $\left(\mathrm{S}^{-} \mathrm{L}^{+}\right)$on the viability of $S$. mutans biofilms. Data represent mean values $(\mathrm{n}=$ 3). b Treatment effects with sensitizer and light $\left(\mathrm{S}^{+} \mathrm{L}^{+}\right)$and without sensitizer and without light $\left(\mathrm{S}^{-} \mathrm{L}^{-}\right)$on the viability of mutans streptococci and total streptococci present in biofilms formed in situ. Data represent mean values $(\mathrm{n}=21)$. Error bars represent SD and data followed by different letters differ statistically $(\mathrm{p}<0.05)$.

between the experimental treatments. To determine the differences between test and control values in the in situ experiment, the unpaired t test was used. Significance level was set at $5 \%(\mathrm{p}<$ 0.05) using the software BIOSTAT 3.0 (Belém, PA, Brazil).

\section{Results}

\section{In vitro Experiment}

The results showed that neither incubation with TBO alone, nor treatment with $55 \mathrm{~J} \mathrm{~cm}^{-2}$ of irradiation, in the absence of a sensitizer, had a significant effect on the vi- 
ability of $S$. mutans $(\mathrm{p}>0.05)$. Significant decreases in the viability of monospecies biofilms were only observed when biofilms were exposed to both TBO and light (fig. 1a) with median viable counts of $1.40 \times 10^{4} \pm 1.27$ $\times 10^{4}(\mathrm{SD})$ in the group submitted to PACT $\left(\mathrm{S}^{+} \mathrm{L}^{+}\right)$contrasting with the other groups as follows: $4.14 \times 10^{9} \pm$ $3.78 \times 10^{9}\left(\mathrm{~S}^{-} \mathrm{L}^{-}\right), 3.68 \times 10^{9} \pm 2.42 \times 10^{9}\left(\mathrm{~S}^{+} \mathrm{L}^{-}\right)$and $1.49 \times 10^{9} \pm 1.36 \times 10^{9}\left(\mathrm{~S}^{-} \mathrm{L}^{+}\right)$. If the log reduction results were calculated by subtraction of $\log _{10}$ counts in the negative control from $\log _{10}$ counts in the other groups, $\log _{10}$ reductions of up to 5.48 were observed when $\mathrm{S}^{-} \mathrm{L}^{-}$ and $\mathrm{S}^{+} \mathrm{L}^{+}$groups were compared.

\section{In situ Experiment}

All volunteers showed normal patterns in the salivary tests with mean values of $1.2 \mathrm{ml} / \mathrm{min}$ salivary flow rate, normal buffering capacity and $1.79 \times 10^{8} \mathrm{CFU} \mathrm{ml}^{-1}$ of mutans streptococci in biofilms formed after $36 \mathrm{~h}$ of oral hygiene suppression. The effect of PACT on viability of the in situ biofilms showed a slight reduction in the microbiological counts for both total streptococci and mutans streptococci (fig. 1b). However, there was no statisti$\mathrm{cal}$ significance between the groups $(\mathrm{p}>0.100)$. For total streptococci, the amount of viable colonies for the PACT

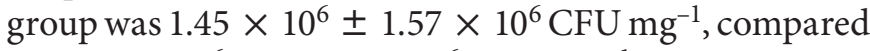
to $2.22 \times 10^{6} \pm 4.21 \times 10^{6} \mathrm{CFU} \mathrm{mg}^{-1}$ for the control group. A similar trend was found for mutans streptococci counts showing $5.26 \times 10^{5} \pm 7.85 \times 10^{5} \mathrm{CFU} \mathrm{mg}^{-1}$ for the PACT group and $8.34 \times 10^{5} \pm 1.15 \times 10^{6} \mathrm{CFU}$ $\mathrm{mg}^{-1}$ for the control. The percentage of mutans streptococci related to total streptococci was $37.56 \%$ in group $\mathrm{S}^{-} \mathrm{L}^{-}$and $36.27 \%$ in group $\mathrm{S}^{+} \mathrm{L}^{+}$.

\section{Discussion}

In the present study, we investigated the antimicrobial photodynamic effect of an LED associated with TBO on in vitro and in situ biofilms. The choice of an LED, instead of a laser device, was determined by its physical characteristics that, associated with its low cost and portability, made it more desirable to be used in PACT. In addition, the lack of collimation and coherence of LEDs, which results in wider bands of emission (620-660 nm), can provide light emission throughout the entire absorption spectrum of the sensitizer [Zanin et al., 2006], which may promote optimization of photodynamic processes Furthermore, Zanin et al. [2005] demonstrated that the use of a HeNe laser or an LED light in association with TBO had the same antimicrobial effect on $S$. mutans biofilm viabil- ity. TBO was chosen as a sensitizer due to its characteristics of an optimal photosensitizer including photophysical, chemical and biological characteristics such as the possibility of local delivery into the infected area, selectivity for microorganisms in low concentrations, avoiding damage to host tissue, and diffusion capacity [O'Neill et al., 2002]. Besides, a recent study demonstrated that TBO, associated with an LED, was the only photosensitizer among those tested at the same molar concentration and irradiation conditions, effective against planktonic cultures of S. mutans [Rolim et al., 2012].

A great number of studies have shown that oral bacteria are susceptible to the action of PACT when suspended in planktonic cultures [Paulino et al., 2005; Rolim et al., 2012], oral biofilms [Wood et al., 1999; O’Neill et al., 2002; Zanin et al., 2005] as well as carious dentine [Lima et al., 2009; Melo et al., 2010]. Our data demonstrated that PACT on in vitro monospecies biofilm was effective in promoting a statistically significant decrease $(p<0.01)$ in the microorganism's viability. Neither irradiation of the organisms in the absence of TBO nor incubation with TBO alone had a significant effect on the viability of S. mutans UA159. Significant log reductions (1-3 log) in the viability of these microorganisms using the same sensitizer and light source were observed in previous studies [Zanin et al., 2005, 2006]. Although there are some variations in the results, possibly due to a change in the method used, PACT was shown to be effective on in vitro monospecies biofilm using the following methods and substrates: constant depth film fermenter - CDFF using HA discs as substrate [Zanin et al., 2005]; batch culture method using enamel blocks as substrate [Zanin et al., 2006]; batch culture method using acrylic discs as substrate [Pereira et al., 2011], and batch culture method using HA discs as substrate (in the present study).

Besides the great reduction of microorganisms reported in the monospecies in vitro biofilms, some studies demonstrate that PACT cannot fully eliminate oral biofilm species, especially when multispecies biofilms are tested [Müller et al., 2007; Qin et al., 2008; Fontana et al., 2009]. In this way, we decided to evaluate the effect of PACT under conditions more similar to those found in the mouth, using an in situ multispecies biofilm model. This method involves the use of devices that create conditions reproducing the process of biofilm formation in the oral cavity, serving as a link between the uncontrolled clinical situation and the highly controlled laboratory experiments. Our choice in evaluating total streptococci counts instead of total viable microorganisms and compare them with mutans streptococci results was based on 
the fact that total streptococci represent the major part of the population in multispecies biofilms [O'Neill et al., 2002] and the predominant genera in mature smoothsurface plaque belong to Actinomyces and Streptococcus, most of which are non-mutans streptococci [XiménezFyvie et al., 2000]. In addition, considering that Tenuta et al. [2003], using a similar 7-day in situ study, have demonstrated a very low proportion of mutans streptococci in total viable microbial counts and that non-mutans streptococci are closely involved in the initiation of caries [Sansone et al., 1993], we decided to investigate the PACT effect not only on mutans streptococci but also on oral streptococci.

Under the same conditions used to treat the in vitro biofilms, PACT was able to show only a trend of reduction in total streptococci and mutans streptococci counts in multispecies in situ biofilms. This is in agreement with Pereira et al. [2011], who evaluated the susceptibility of single- and multispecies in vitro biofilms to the antimicrobial effect of photodynamic therapy and found that the highest reductions in microorganism viability were demonstrated for single-species biofilms. Also, Fontana et al. [2009], testing the antimicrobial effect of photodynamic therapy on pooled dental plaque suspensions and on multispecies biofilms, found that oral bacteria in multispecies biofilms are also little affected by PACT.

Müller et al. [2007] tested different antimicrobial treatments to kill microorganisms present in multispecies oral biofilms formed in vitro. PACT treatment using methylene blue followed by irradiation with diode soft laser was compared with gasiform vacuum-ozone, chlorhexidine and hypochlorite treatments. As expected, only the $5 \%$ hypochlorite solution was able to totally eliminate the microorganisms in the multispecies biofilms and the observed reduction of viable counts by photodynamic therapy was less than one $\log _{10}$ step, having minimal effect on the viability of organized biofilms. However, although PACT was shown to be 3 - to 4 -fold less effective for dense multispecies biofilms formed in situ than for in vitro monospecies biofilms, the antibiotics have been reported to be approximately 250 -fold less effective under these conditions [Sedlacek and Walker, 2007].

On the other hand, Wood et al. [1999] observed by confocal microscopy images that PACT was able to eliminate a very large number of microorganisms in multispecies biofilms formed in situ, although, in the latter study, no quantitative technique was performed. A significant antimicrobial effect of PACT on multispecies biofilms was also obtained by O'Neill et al. [2002] in an in vitro model where the authors related that antimicrobial effect occurred predominantly in the outer layers of the biofilm.

Once the presence of bacteria in a multispecies biofilm may promote the emergence of specific features that set lower susceptibility to PACT, differences in biofilm thickness may also have an important role on the antimicrobial effect of photodynamic therapy. Several authors demonstrate that lethal photosensitization occurred predominantly in the outer layers of the biofilms, leaving some of the innermost bacteria alive, which may be due to the inability of the photosensitizer to diffuse through into these inner regions [Zanin et al., 2005; Pereira et al., 2011]. Considering that in our in vitro study, $100-\mu \mathrm{m}$ thickness biofilms were produced after 5 days of growing while, after a similar time of growing, $1,000-\mu \mathrm{m}$-thickness biofilms were obtained in situ, it can be suggested that biofilm thickness is one potential problem associated with the inefficiency of photodynamic therapy in the in situ biofilms tested. However, this could be overcome by selecting a photosensitizer able to penetrate through the biofilm matrix, and by using alternative tools to improve photosensitizer penetration such as photomechanical waves [Soukos et al., 2003], as well as by irradiating biofilm internally via an optical fiber instead of from the biofilm surface [O’Neill et al., 2002].

In conclusion, the same dose of PACT was effective in killing oral microorganisms present in S. mutans biofilms grown in vitro and not effective in killing oral streptococci present in multispecies biofilms grown in situ. Although the in situ model mimics the natural adversity encountered in the oral cavity, clinical response of the therapy in an in vivo experiment may be different. Thus further research is required before therapy can be used clinically, especially those related with finding appropriate dosage parameters and also fully understanding the mechanism of action of PACT.

\section{Acknowledgments}

This research was supported by CNPq 478312/2007-5 and FUNCAP BPI-0187-4.02/08. We thank all the volunteers for their valuable contribution. The authors also thank Ruliglesio Rocha and Flaviana Bezerra for their help with experimental procedures.

\section{Disclosure Statement}

There are no potential conflicts of interest relating to this study. 


\section{References}

- Aires CP, Del Bel Cury AA, Tenuta LMA, Klein MI, Koo H, Duarte S, Cury JA: Effect of starch and sucrose on dental biofilm formation and root dentine demineralization. Caries Res 2008;42:380-386.

Cury JA, Rebello MA, Del Bel Cury AA, Derbyshire MT, Tabchoury CP: Biochemical composition and cariogenicity of dental plaque formed in the presence of sucrose or glucose and fructose. Caries Res 2000;34: 491-497.

Duarte S, Klein MI, Aires CP, Cury JA, Bowen $\mathrm{WH}, \mathrm{Koo} \mathrm{H}$ : Influences of starch and sucrose on Streptococcus mutans biofilms. Oral Microbiol Immunol 2008;23:206-212.

- Fontana CR, Abernethy AD, Som S, Ruggiero K, Doucette S, Marcantonio RC, Boussios CI, Kent R, Goodson JM, Tanner ACR, Soukos NS: The antibacterial effect of photodynamic therapy in dental plaque derived biofilms. J Periodontal Res 2009;44:751-759.

Lemos JA, Burne RA: A model of efficiency: stress tolerance by Streptococcus mutans. Microbiology 2008;154:3247-3255.

- Lima JPM, Sampaio de Melo MA, Borges FMC, Teixeira AH, Steiner-Oliveira C, Nobre dos Santos M, Rodrigues LKA, Zanin ICJ: Evaluation of the antimicrobial effect of photodynamic antimicrobial therapy in an in situ model of dentine caries. Eur J Oral Sci 2009; 117:568-574.

Melo MAS, de-Paula DM, Lima JPM, Borges FMC, Steiner-Oliveira C, Nobre dos Santos M, Zanin ICJ, Barros EB, Rodrigues LKA: In vitro photodynamic antimicrobial chemotherapy in dentine contaminated by cariogenic bacteria. Laser Physics 2010;20:15041513.

Müller P, Guggenheim B, Schmidlin PR: Efficacy of gasiform ozone and photodynamic therapy on a multispecies oral biofilm in vitro. Eur J Oral Sci 2007;115:77-80.
O’Neill JF, Hope C, Wilson M: Oral bacteria in multi-species biofilms can be killed by red light in the presence of toluidine blue. Lasers Surg Med 2002;3:86-90.

Paulino TP, Ribeiro KF, Thedei G Jr, Tedesco AC, Ciancaglini P: Use of hand held photopolymerizer to photoinactivate Streptococcus mutans. Arch Oral Biol 2005;50:353-359.

- Pereira CA, Romeiro RL, Costa AC, Machado AK, Junqueira JC, Jorge AO: Susceptibility of Candida albicans, Staphylococcus aureus, and Streptococcus mutans biofilms to photodynamic inactivation: an in vitro study. Lasers Med Sci 2011;26:341-348.

- Pratten J, Wilson M, Spratt DA: Characterization of in vitro oral bacterial biofilms by traditional and molecular methods. Oral Microbiol Immunol 2003;18:45-49.

Qin YL, Luan XL, Bi LJ, He G, Bai X, Zhou CN, Zhang ZG: Toluidine blue-mediated photoinactivation of periodontal pathogens from supragingival plaques. Lasers Med Sci 2008; 23:49-54.

Rolim JP, de-Melo MA, Guedes SF, Albuquerque-Filho FB, de Souza JR, Nogueira NA, Zanin IC, Rodrigues LK: The antimicrobial activity of photodynamic therapy against Streptococcus mutans using different photosensitizers. J Photochem Photobiol B 2012; 106:40-46.

Sansone C, Van Houte J, Joshipura K, Kent R, Margolis HC: The association of mutans streptococci and non-mutans streptococci capable of acidogenesis at a low $\mathrm{pH}$ with dental caries on enamel and root surfaces. J Dent Res 1993;72:508-516.

Sedlacek MJ, Walker C: Antibiotic resistance in an in vitro subgingival biofilm model. Oral Microbiol Immunol 2007;22:333-339.

Shemesh M, Tam A, Steinberg D: Differential gene expression profiling of Streptococcus mutans cultured under biofilm and planktonic conditions. Microbiology 2007;153: 1307-1317.
Soukos NS, Mulholland SE, Socransky SS, Doukas AG: Photodestruction of human dental plaque bacteria: enhancement of the photodynamic effect by photomechanical waves in an oral biofilm model. Lasers Surg Med 2003;33:161-168

Sousa RP, Zanin IC, Lima JP, Vasconcelos SM, Melo MA, Beltrão HC, Rodrigues LK: In situ effects of restorative material on dental biofilm and enamel demineralization. J Dent 2009;37:44-51.

Tenuta LMA, Lima JEO, Cardoso CL, Tabchoury COM, Cury JA: Effect of plaque accumulation and salivary factors on enamel demineralization and plaque composition in situ. Pesqui Odontol Bras 2003;17:326-331.

Wilson BC, Patterson MS: The physics, biophysics and technology of photodynamic therapy. Phys Med Biol 2008;53:R61-R109.

Wood S, Nattress B, Kirkham J, Shore R, Brookes S, Griffiths J, Robinson C: An in vitro study of the use of photodynamic therapy for the treatment of natural oral plaque biofilms formed in vivo. J Photochem Photobiol B 1999;50:1-7.

Ximénez-Fyvie LA, Haffajee AD, Socransky SS: Microbial composition of supra- and subgingival plaque in subjects with adult periodontitis. J Clin Periodontol 2000;27:722-732.

Zanin IC, Gonçalves RB, Junior AB, Hope CK, Pratten J: Susceptibility of Streptococcus mutans biofilms to photodynamic therapy: an in vitro study. J Antimicrob Chemother 2005;56:324-330.

Zanin IC, Lobo MM, Rodrigues LK, Pimenta LA, Hofling JF, Gonçalves RB: Photosensitization of in vitro biofilms by toluidine blue O combined with a light-emitting diode. Eur J Oral Sci 2006;114:64-69.

Zaura-Arite E, van Marle J, ten Cate JM: Confocal microscopy study of undisturbed and chlorhexidine-treated dental biofilm. J Dent Res 2001;80:1436-1440. 